\title{
O ensaio como estratégia de leitura, pesquisa e escrita
}

\author{
The essay as strategy of reading, research and writing
}

\author{
Ana Márcia Martins da SiLVA \\ Pontifícia Universidade Católica do Rio Grande do Sul, Porto Alegre, RS
}

Resumo: Este artigo discute uso do gênero textual ensaio aos estudantes de Ensino Médio (EM) e estudantes de graduação em língua portuguesa. Este gênero textual, além de exigir autoria, também requer bagagem cultural, obtida através da leitura e pesquisa. No EM, as produções trataram temas de interesse para os adolescentes (linguagem da internet e questões culturais do estado em que moram) e na universidade, questões pertinentes à qualificação do professor de língua portuguesa. Nós tentamos usar estratégias que evitem a gramaticalização do gênero textual, como vamos mostrar no relato das experiências com estudantes de $2^{\underline{a}}$ e $3^{\underline{a}}$ séries do EM e com alunos de graduação em disciplinas do terceiro e quinto semestres, identificadas aqui respectivamente como DI e DII. Este artigo está organizado em duas seções. Na primeira, vamos discutir brevemente as contribuições teóricas para o conceito do gênero textual ensaio, uma vez que estamos preocupados com a reflexão sobre as práticas de escrita motivadas pela necessidade de um ponto de vista claro sobre o tema. Na segunda parte, apresentamos o relato de experiências em dois níveis diferentes de ensino - EM e universidade - que tinham um objetivo geral comum, mas diferentes objetivos específicos. Nas considerações finais, tentaremos analisar os resultados obtidos com essas experiências.

Palavras-chave: Ensaio; Gênero textual; Leitura; Pesquisa; Escrita

\begin{abstract}
This paper discusses the use of the essay by High School and undergraduate students of Portuguese language. This textual genre, besides demanding a clear authorship, also requires cultural knowledge, obtained through reading and research. In HS, the texts dealt with topics of interest to teenagers (Internet language and cultural issues in the state where they live). At university, the themes were pertinent to the qualification of teachers of Portuguese language. We tried to use strategies that avoid the grammaticalization of the textual genre, as we are going to show in the report of the experiences with 2nd and 3rd grade students of HS and with third and fifth semester undergraduate students, identified here respectively as DI and DII. This article is organized in two sections. In the first one, we are going to briefly discuss the theoretical contributions to the concept of the essay as a textual genre, since we are concerned here about reflecting on the writing practices motivated by the need for a clear point of view on the matter. In the second part, we present the report of experiences at two different levels of teaching - HS and university - which had a common general objective, but different specific objectives. In the final considerations, we will try to analyze the results obtained with such experiences.
\end{abstract}

Keywords: Essay; Textual genre; Reading; Research; Writing

“O ensino gramatical é, na prática, a única solução que a escola tem dado à necessidade de ensinar a norma culta, num contexto linguístico em que a norma culta se afasta do uso corrente."

ILARI e BASSO, 2007, p. 235. 


\section{Considerações iniciais}

É possível ensinar o português brasileiro (doravante PB) aos brasileiros? É necessário ensinar a língua que já conhecemos? Ora, todos temos a capacidade da linguagem, que nos permite aprender qualquer língua, e isso, por si só, nos leva à conclusão de que "aprender" pressupõe "ensinar". Então, sim, ensinamos o PB, mas a variante padrão, esta que, por não ser a empregada diariamente, amedronta os alunos não proficientes e os afasta de aulas de língua portuguesa, seja no ensino médio (EM), seja na universidade. Não há, para eles, funcionalidade em estudar regras aparentemente inúteis, uma vez que as veem repetidas, a cada novo ano escolar ou a cada nova disciplina dedicada ao PB na universidade, sem apreendê-las e sem conseguir aplicá-las nas frases e textos que tentam construir.

E foi para aproximar esses falantes nativos da variante padrão do PB que, tanto no ensino médio quanto na universidade, nos valemos do trabalho com gêneros textuais, procurando considerar sempre o contexto envolvido. Segundo Koch; Elias (2010, p. 61), “dominar um gênero consistiria no próprio domínio da situação comunicativa [...] e a escolha do gênero, portanto, deverá levar em conta cada caso, os objetivos visados, o lugar social e os papéis dos participantes". Assim, o objetivo é tornar esses falantes, de qualquer um dos níveis de ensino, proficientes no emprego da variante padrão, mas "o lugar social e os papéis dos participantes" determinam estratégias e temas diferentes. Afinal, trata-se de dois níveis de ensino com interesses diferentes: "os participantes" do ensino médio (EM), em geral, querem qualificar sua produção escrita para chegar à universidade, e os da universidade querem se qualificar para ascender profissional e socialmente.

$O$ gênero textual escolhido foi o ensaio porque, além de pressupor autoria, exige também bagagem cultural, obtida via leitura e pesquisa. No EM, as produções versavam sobre assuntos de interesse dos adolescentes (linguagem da Internet e questões culturais do estado em que residem), e, na universidade, sobre questões pertinentes à formação do professor de língua portuguesa. Procuramos utilizar estratégias que evitassem a gramaticalização do gênero textual, conforme demonstraremos no relato das experiências realizadas com alunos da $2^{\underline{a}}$ e $3^{\underline{a}}$ séries do EM e com acadêmicos da licenciatura em língua portuguesa em disciplinas do $3^{\circ}$ e do $5^{\circ}$ semestres, identificadas aqui, respectivamente, como DI e DII.

Este artigo está organizado em duas seções. $\mathrm{Na}$ primeira, discutiremos brevemente os aportes teóricos para o conceito do gênero textual ensaio, já que nos importa aqui refletir sobre as práticas de escrita motivadas pela necessidade de uma demarcação de posicionamento. $\mathrm{Na}$ segunda, apresentaremos o relato de experiências realizadas em dois níveis diferentes de ensino - EM e universidade -, as quais tinham um objetivo geral comum, mas objetivos específicos diferentes. Nas considerações finais, procuraremos analisar os resultados obtidos com tais experiências.

\section{$O$ gênero textual ensaio}

Tipo de texto e gênero textual, apesar de terem conceitos diferentes, são dependentes um do outro, como os dois lados de uma moeda. Levando-se em conta a interatividade da língua, no dizer de Marcuschi (2008, p. 154), “é impossível se comunicar verbalmente a não ser por algum gênero, assim como é impossível se comunicar verbalmente a não ser por algum texto". E como se pode diferenciar um texto de um gênero textual? É simples: este é definido por suas propriedades sociocomunicativas, sendo gerado apenas em situações de comunicação; aquele tem seus tipos definidos pelos aspectos linguísticos de sua composição (tempos verbais, por exemplo). Mas, na prática de sala de aula, é mesmo necessário centrarmos a produção escrita na diferenciação entre gêneros e tipos textuais?

Acreditamos na prática da produção escrita, que naturalmente levará à escolha do tipo de texto, no caso do EM, mas, em se tratando da licenciatura em letras, precisamos estabelecer essas diferenças não só como estratégia de ensino, para que nossos futuros professores sejam produtores de textos, mas também como instrução para a produção de conhecimento que será levada a efeito por eles em suas salas de aula, tornando-os capazes de orientar adequadamente seus alunos. Deixamos claro, portanto, que o enfoque do trabalho com o gênero ensaio é diferenciado em cada um dos níveis aqui retratados. E a escolha recaiu sobre o ensaio porque, como já dissemos, ele não só contempla a leitura de outros gêneros, já que o autor precisará movimentar sua bagagem cultural para compor seu trabalho, como envolve a defesa de um ponto de vista, o que determinará a escolha do tipo textual bem como da linguagem a ser utilizada para persuadir o seu leitor.

E por que o ensaio apresenta tais propriedades? Desde o surgimento, com Montaigne (1580), e do seu auge, com os filósofos iluministas, como Rousseau, com o "Ensaio sobre a origem das línguas" (2003), este gênero vem sendo utilizado pelas mais variadas áreas, não sem gerar controvérsias, uma vez que críticos há a sua banalização, como Meneghetti (2011, p.321).

Da época de Montaigne até a atualidade, os ensaios adquiriram diversas formas e formatos, assim como 
são utilizados para diversos fins: literários, filosóficos, científicos etc. Essas variações nas formas e formatos, assim como a multiplicidade nas suas utilizações, levam a concepções e usos equivocados desse estilo e forma de refletir a realidade.

Diferente do método tradicional da ciência, em que a forma é considerada mais importante que o conteúdo, o ensaio requer sujeitos, ensaísta e leitor, capazes de avaliarem que a compreensão da realidade também ocorre de outras formas. (Grifos nossos)

Entretanto, ousamos discordar dessa crítica, pois é exatamente por requerer "sujeitos, ensaísta e leitor, capazes de avaliarem que a compreensão da realidade também ocorre de outras formas" que o ensaio é tão utilizado, independentemente da área ou do nível escolar de seu autor. Obviamente que, ao solicitarmos a redação de um ensaio, teremos o cuidado de não exigir de seus autores construções que vão além de sua capacidade de conhecimento. Isso, no entanto, longe de ser negativo, é uma grande contribuição para a qualidade das reflexões daqueles que são solicitados a escrever tal gênero.

No texto "Produção acadêmico-científica: a pesquisa e o ensaio", publicado em Cadernos de Ensino da Universidade do Vale do Itajaí (2011, p.87, 88, 99), encontram-se algumas características desse gênero que consideramos as grandes motivadoras das experiências que realizamos com nossos alunos do EM e da licenciatura em Letras, quais sejam, (1) o caráter dialogal do ensaio, (2) o ensaio como forma de pensar e (3) a desnecessidade de comprovação empírica.

No EM, propor a escrita de um gênero essencialmente dialogal como forma de organizar o pensamento foi determinante para a adesão dessa geração de adolescentes que vive conectada, via dispositivos móveis e computadores, aos seus iguais e ao resto do mundo que a cerca. A produção do ensaio fluiu com naturalidade, sem que seus autores a considerassem um sacrifício ou uma tortura. Por meio dela, com o intuito de melhorá-la, tornando o conteúdo mais claro ao seu leitor, foi possível trabalhar as estruturas da língua em uso. Motta-Roth (2010:496) afirma que "Tal conceito de linguagem, que articula a vida social e o sistema da língua, carrega em si pressupostos acerca do ensino de linguagem: ensinar uma língua é ensinar a agir naquela língua".

Já, na licenciatura em Letras, além das características (1) e (2), também a (3) foi fundamental, porque permitiu aos acadêmicos uma reflexão sobre o que haviam trabalhado em aula e sobre os textos lidos nas disciplinas. Esse fator deu-lhes tranquilidade para escrever sobre os tópicos sugeridos para o ensaio e serviu como um treinamento para o trabalho de conclusão de curso, que, embora solicite uma monografia, também exige a reflexão sobre determinada situação de ensino suscitada durante a graduação. Precisamos de professores que saibam refletir sobre o conhecimento adquirido na licenciatura e que consigam estabelecer novas relações a partir deles, estas que terão como fim guiá-los na sua vida profissional. É lugar-comum dizer que nunca estamos prontos, mas não o é dizer que devemos construir nosso caminho sobre as bases que nos foram dadas, seja para ampliá-las, seja para refutá-las.

É o que traz, por exemplo, Lago Jr. (1990, p.6), quando se refere à tarefa do ensaísta.

Do repertório de temas escolhidos para criar e trabalhar, combina, adapta, expande e recria concepções e interpretações próprias ou alheias. Registra, também, impressões e conclusões de suas leituras ou de suas conversações interiores ou do diálogo imaginário com outros autores, com pensamentos e argumentações que se desdobram ao longo de seu processo criador.

Era essa a nossa intenção ao propor tais trabalhos a nossos alunos. Teremos conseguido? Na seção a seguir, faremos o resgate das experiências realizadas, o que nos levará, ao final deste artigo, a uma possível resposta para essa pergunta. Primeiro apresentaremos os trabalhos realizados no EM, que envolveram, respectivamente, a redação de um ensaio curto - "um texto que exponha ou discuta ideias sobre um determinado tema e que tenha um tamanho variável entre quatro e dez parágrafos" (MORENO e GUEDES. 2004, p. 27) - e de um ensaio documentado - "um trabalho escrito que se baseia em conhecimentos adquiridos através de pesquisa bibliográfica" (MORENO e GUEDES. 2004, p.35). Depois, traremos a redação do ensaio documentado em duas disciplinas da licenciatura em Letras, DI e DII, respectivamente.

\section{O ensaio no EM - a reflexão sobre o mundo que nos cerca}

\section{Um}

Um dos projetos, o "Dicionário da Linguagem do MSN", aplicado em 2008, quando essa ferramenta de comunicação ainda era utilizada, procurou lidar com a relação dos alunos com a linguagem virtual, no intuito de mostrar a eles que tal linguagem não era um "assassinato da Língua Portuguesa", e sim uma variação adequada ao ambiente virtual, e apenas a ele. O público-alvo eram as

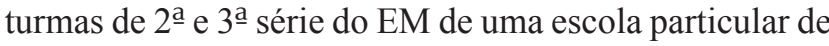
Porto Alegre. No Quadro 1, apresentamos os objetivos e a justificativa do projeto. 
Quadro 1. Objetivos e justificativa do projeto "Dicionário da Linguagem do MSN"

\section{OBJETIVOS}

1.1 Definir o MSN e sua linguagem

1.2 Comparar opiniões favoráveis à linguagem do MSN com as contrárias a ela.

1.3 Redigir verbetes com a tradução dessa linguagem para o Português culto.

1.4 Comparar a eficiência dessas duas linguagens em ambientes diferentes.

1.5 Redigir ensaio curto manifestando-se sobre a relevância - ou não - da utilização da linguagem do MSN.

1.6 Utilizar as tecnologias disponibilizadas pela escola.

2. JUSTIFICATIVA

Esta atividade envolverá o trabalho com a gramática do Português do Brasil (PB) e com a do MSN, permitindo aos alunos a comparação entre as duas e a escolha pela utilização de cada uma no(s) ambiente(s) em que eles estiverem. Assim, poderão transitar mais tranquilamente entre elas, permitindo que uma interfira na outra apenas quando for necessário, evitando, portanto, que seus textos na escola sejam redigidos numa língua que não o Português culto.

Os objetivos e a justificativa para o projeto foram devidamente discutidos em sala de aula com todas as turmas de segundas e de terceiras séries do EM. Deixamos claro a elas, portanto, que o trabalho estava vinculado à produção textual (1.5), com a redação do ensaio, bem como às questões pertinentes à língua materna $(1.3$, 1.4), estas que envolveriam o emprego adequado de um vocabulário que traduzisse a linguagem do MSN, utilizando-nos aqui de mais um gênero textual, o verbete. Durante um trimestre, trabalhamos com o tema, seguindo as etapas discriminadas no Quadro 2.

Quadro 2. Etapas do projeto "Dicionário da Linguagem do MSN"

\begin{tabular}{|c|}
\hline “DICIONÁRIO DA LINGUAGEM DO MSN” \\
\hline CRONOGRAMA \\
\hline O trabalho terá o seguinte cronograma: \\
\hline 1. Pesquisa, na Internet, sobre \\
\hline 1.1 o programa MSN (definição, utilizações). \\
\hline $\begin{array}{l}1.2 \text { os winks e os emoticons (o que são, como surgiram e para } \\
\text { que servem). }\end{array}$ \\
\hline 1.3 opiniões favoráveis à linguagem do MSN e contrárias a ela. \\
\hline $\begin{array}{l}\text { 2. Levantamento do vocabulário e dos sinais utilizados nas conversas } \\
\text { no MSN. }\end{array}$ \\
\hline 3. Redação dos verbetes - de A a Z - com sinônimos em PB. \\
\hline $\begin{array}{l}\rightarrow \text { Na segunda e na terceira aulas no Laboratório de Informática. } \\
\text { 4. Elaboração de um pequeno texto narrativo - nas duas linguagens }\end{array}$ \\
\hline $\begin{array}{l}\text { - para verificação da eficiência de cada um quando utilizado em } \\
\text { ambiente diferente daquele a que pertence. }\end{array}$ \\
\hline $\begin{array}{l}\rightarrow \text { Em sala de aula, nos períodos de Redação elou de Língua } \\
\text { Portuguesa. }\end{array}$ \\
\hline 5. Aplicação do instrumento de pesquisa elaborado no item 4. \\
\hline $\begin{array}{l}\rightarrow \text { Na quarta aula no Laboratório de Informática e em sala de } \\
\text { aula, em Red. e/ou LP. }\end{array}$ \\
\hline $\begin{array}{l}\text { 6. Redação do ensaio curto a partir das constatações feitas durante } \\
\text { as etapas } 1,2,3,4 \text { e } 5 \text {. }\end{array}$ \\
\hline $\begin{array}{l}\rightarrow \text { Em sala de aula, nos períodos de Redação e/ou de Língua } \\
\text { Portuguesa. }\end{array}$ \\
\hline 7. Editoração do dicionário no Laboratório de Informática. \\
\hline $\begin{array}{l}\rightarrow \text { Na quinta aula no Laboratório de Informática. } \\
\text { 8. Entrega do trabalho em } 28 / 4 / 2008 \text {. }\end{array}$ \\
\hline $\begin{array}{l}\text { 9. Lançamento do dicionário em evento a ser programado pelas } \\
\text { disciplinas envolvidas, em conjunto com a Equipe Diretiva. }\end{array}$ \\
\hline
\end{tabular}

Pela distribuição do cronograma, podemos perceber que a redação do ensaio foi baseada nas reflexões que foram sendo feitas a partir das etapas 1, 2, 3, 4 e 5. Essa redação, portanto, surgiu da necessidade de organizar as ideias sobre o tema e de expressar um ponto de vista. O trabalho foi sempre mediado via tecnologias da informação, seja por e-mail, seja pelo próprio MSN, e os alunos trocavam constantes impressões com a professora, que também escrevia seu ensaio. No Quadro 3, reproduzimos uma dessas mensagens.

\section{Quadro 3. Mensagens de alunas da 2a série do EM}

Oi Sora. Como tu tinhas pedido para usar na tua pesquisa/ensaio curto, segue a nossa história traduzida para a linguagem do MSN (...)

(linguagem virtual - aliás, pelo teu interesse especial neste tipo de linguagem que usamos, achamos interessante te dar a dica de pesquisar um pouco sobre "Tiopês", uma variação bem atual e meio irônica da transferência da fala para o virtual) (Lia \& Lea*, 2008.)

* Os nomes foram trocados para preservar a identidade das alunas.

A mensagem enviada via Ambiente Virtual de Aprendizagem (AVA) pelas meninas Lia e Lea demonstra o grau de interesse dos alunos da segunda série. Elas foram além do solicitado, apresentando uma "dica" que a professora pudesse incluir no ensaio que escreveria. Observemos que os sujeitos da comunicação estão bem marcados na mensagem: "teu interesse pessoal neste tipo de linguagem que usamos", o que podemos traduzir como "tu te interessas pela forma como nos comunicamos". Estabelecera-se o diálogo entre os alunos, nas etapas 4 e 5, bem como com a professora. E o ensaio ampliaria esse diálogo, pois serviria de apresentação para o dicionário, que seria lançado e divulgado na comunidade escolar.

\section{Outro}

O projeto de maior sucesso com os alunos e com melhor resultado, ainda em 2008, foi o ensaio documentado sobre a origem do espírito separatista do gaúcho ${ }^{1}$. O público-alvo foi apenas a segunda série, e as turmas se envolveram muito na realização da pesquisa. Descobriram informações sobre a história do Rio Grande do Sul e faziam questão de mostrar para os colegas e para a professora. No dia da entrega, estavam orgulhosos de sua produção. No Quadro 4, encontram-se as orientações para o trabalho, que, dessa vez, exigia mais autonomia porque não seria feito em aula.

\footnotetext{
$<$ https://pt-br.facebook.com/O-Rio-Grande-\%C3\%A9-o-MEUPA\%C3\%8DS-371312576234319/>. 
Quadro 4. Projeto do ensaio documentado

\section{ATIVIDADE EXTRACLASSE - PESQUISA E REDAÇÃO DE ENSAIO DOCUMENTADO}

OBJETIVO: Pesquisar sobre a origem do espírito separatista do gaúcho e redigir um ensaio documentado.

Chamamos de ensaio documentado um trabalho escrito que se baseia em conhecimentos adquiridos através de pesquisa bibliográfica. Diferentemente do ensaio curto, que se organiza a partir de sua capacidade de pôr em ação conhecimentos que você já tem, o ensaio documentado movimenta, também, sua capacidade de coletar e utilizar dados. Sua elaboração é mais vagarosa do que a do ensaio curto; sua extensão dependerá exclusivamente da complexidade do assunto e da quantidade de dados disponíveis (MORENO, C.; GUEDES, P. C. Curso básico de redação. São Paulo: Ática, 1986. p.35).

INSTRUÇÕES:

1. Pesquise sobre a origem do espírito separatista do gaúcho.

2. Utilize os dados de sua pesquisa para redigir um ensaio documentado, cuja estrutura está disponível no Ambiente Virtual de Aprendizagem e na reprografia.

3. Siga as normas estabelecidas pela escola para digitação e apresentação de trabalhos.

4. Não copie trabalhos já prontos, pois seu ensaio não será considerado.

5. Entregue seu ensaio até a data de 31/10/2008

Embora os alunos tivessem de realizar a atividade extraclasse, o contato entre eles e a professora ocorreu sempre, fosse por e-mail fosse pelo MSN. Foi extremamente gratificante atendê-los por essa ferramenta, porque ali era nosso ponto de encontro. Combinamos que, mesmo que a professora estivesse off-line, eles deveriam deixar recado para ela, que retornaria a mensagem. No Quadro 5, reproduzimos a mensagem enviada por e-mail pela aluna Leila ${ }^{2}$, de uma das turmas, sobre a redação do ensaio e sobre a pesquisa.

Quadro 5. Mensagem de aluna pedindo orientações sobre o ensaio

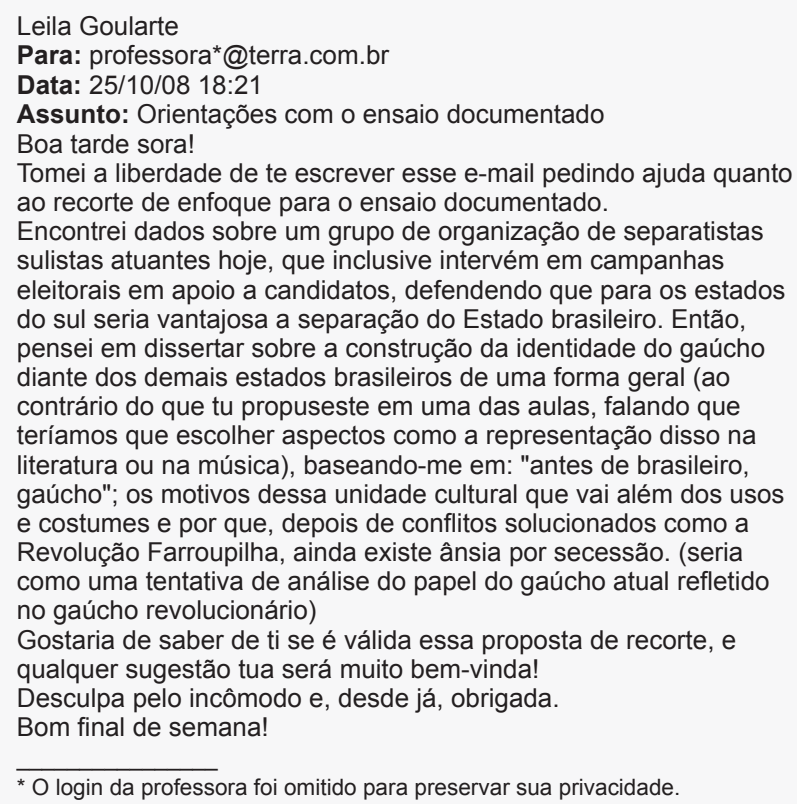

Gostaria de saber de ti se é válida essa proposta de recorte, e

qualquer sugestão tua será muito bem-vinda!

Desculpa pelo incômodo e, desde já, obrigada.

Bom final de semana!

$\bar{*}$ O login da professora foi omitido para preservar sua privacidade.

\footnotetext{
O nome foi trocado para preservar a identidade da aluna.
}

As sucessivas versões dos textos, durante o processo de redação do ensaio, eram enviadas à professora, que as devolvia com comentários. Íamos trabalhando, assim, as estruturas da variante padrão do $\mathrm{PB}$, mas respeitando a individualidade de cada um, considerando suas escolhas lexicais e as marcas de subjetividade no texto. Podemos observar, nas considerações finais de um dos ensaios (Quadro 6), o posicionamento de sua autora e a clara tentativa de uma escrita na variante padrão da língua.

Quadro 6. Considerações finais de um dos ensaios sobre o espírito separatista do gaúcho

\section{CONSIDERAÇÕES FINAIS}

As informações trazidas até aqui nos levam a concluir que o movimento separatista, juntamente com a Revolução Farroupilha tinham o principal objetivo de garantir aos gaúchos uma vida digna e uma sociedade valorizada e ainda fazer com que a nossa cultura seja se propague. A partir disso devemos valorizar as conquistas deixadas a nós e lutar, com consciência, pelo nosso tão sonhado povo-nação.

(Aluna A, turma 222)

O parágrafo revela o cuidado em demonstrar que a conclusão a que chega a autora está baseada em pesquisa, quando afirma que são "As informações trazidas" que levam a concluir sobre o principal objetivo do movimento separatista e da Revolução Farroupilha. Tal indicação é reforçada com a locução "a partir disso" para corroborar o ponto de vista defendido no ensaio, qual seja, "valorizar as conquistas deixadas a nós e lutar, com consciência, pelo nosso tão sonhado povo-nação". Como esta ainda não era a versão final, sinalizamos à Aluna $\mathrm{A}$ alguns ajustes a serem feitos nas frases, como a eliminação da vírgula aposta depois de "movimento separatista" (ou a inclusão de uma depois de "Revolução Farroupilha") e da duplicidade de verbos no final do primeiro período. As idas e vindas das versões objetivavam mostrar aos alunos que "ensinar uma língua é ensinar a agir naquela língua" (Motta-Roth 2010:496) e que esse agir pressupõe "engenharia", "arquitetura", "artesanato" com a língua. Analisar linguisticamente uma frase passou a ter significado, o de melhor comunicar aquilo que se quer dizer.

\section{Ensaio documentado na licenciatura em língua portuguesa - uma reflexão sobre a prática do professor de $\mathrm{PB}$}

“(...) o professor de língua materna deveria ser, por definição, alguém que redige de maneira satisfatória (isto é, com bom controle sobre a correção, a coesão textual, a coerência, e sobre as qualidades do texto que possam ser contextualmente relevantes - concisão, clareza, expressividade...); alguém que interpreta, buscando no texto as informações que importam; alguém que sabe esclarecer a língua de um texto (não apenas a sintaxe das sentenças, e não qualquer 
coisa na língua de um texto, de preferência as coisas que fazem diferença); alguém que sabe e gosta de narrar, descrever e argumentar. Se nos for permitida a analogia, um professor de língua materna tem de ser como um professor de música que... toca.” (ILARI e BASSO, 2007, p. 235).

\section{$\boldsymbol{U} \boldsymbol{m}$}

Em DI, os acadêmicos do terceiro semestre do curso de licenciatura em letras têm como conteúdo o estudo da oração e de seus constituintes (padrões oracionais, funções, sintaxe de concordância e sintaxe de regência), pontuação e particularidades sintáticas na linguagem formal e coloquial. A metodologia de trabalho envolve sempre a ligação com o ensino e a associação de estudos teóricos e análise de evidências dos usos linguísticos nos textos, bem como a investigação de possibilidades e limitações no tratamento de fenômenos sintáticos em diferentes modelos teóricos. São três os modelos teóricos a partir dos quais se discutem os fenômenos sintáticos que envolvem a oração, estruturalismo, gerativismo e funcionalismo. O Quadro 7 traz uma exemplificação de análise sintática em cada um desses modelos teóricos.

\section{Quadro 7. Exemplos de análise sintática}

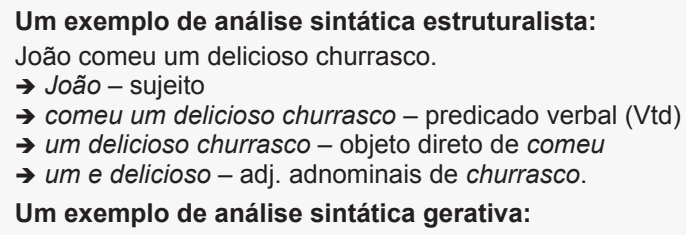

a)

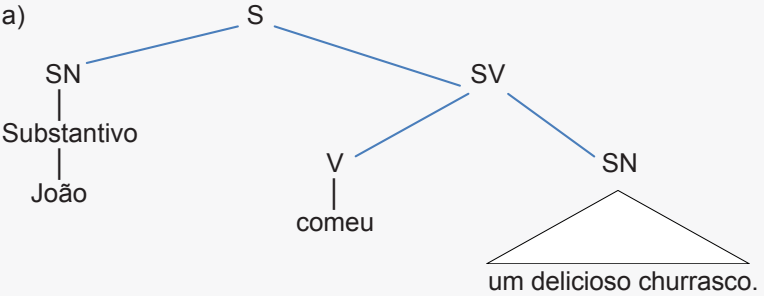

b) [[SN João] [sv comeu [SN um delicioso churrasco]]]

Veja como o funcionalismo explica a diferença entre duas sentenças aparentemente com o mesmo significado.

- Você é desonesto.

- Desonesto é você.

"[...] Ocorre que, ao contrário do que acontece em (a), que constitui uma afirmativa, a sentença (b) está relacionada a uma situação comunicativa típica de réplica, marcada pela inversão do predicado 'desonesto', que vai para o início da frase. Isso significa que essa sentença só faz sentido em um contexto em que o interlocutor tenha feito anteriormente o mesmo insulto. Esse exemplo demonstra a essência da análise funcionalista, que amplia seu campo de visão, recorrendo ao contexto de uso o qual, por hipótese, motiva as mesmas estruturas sintáticas." (CUNHA, 2010, p. 157-158).

Ao examinarmos as possibilidades e limites de diferentes modelos linguísticos, em especial das abordagens tradicionais, para análise da estrutura e do fun- cionamento da língua portuguesa, tendo como eixo a sintaxe, procuramos guiar nossos futuros professores por caminhos que levem à reflexão e à formação continuada. E a proposta de redação de um ensaio, no final da disciplina, é um desses caminhos, que foi "trilhado" em duplas, na biblioteca ou em sala de aula. No Quadro 8, apresentamos as orientações para a redação do ensaio.

Quadro 8. Orientações para a redação do ensaio sobre ensino de sintaxe

PESQUISA E REDAÇÃO DE ENSAIO DOCUMENTADO
INSTRUÇÕES:
1. Utilize os conhecimentos adquiridos durante o semestre e a leitura
do Manual de linguística que você selecionou para escrever um
ensaio justificando a escolha de uma das teorias linguísticas
estudadas - Estruturalismo, Gerativismo ou Funcionalismo - como
suporte para o ensino de sintaxe na educação básica (EF e/ou
EM).
2. Mantenha seu ensaio no limite entre 30 e 60 linhas (manuscritas
ou digitadas).
3. Não copie trabalhos já prontos, pois seu trabalho não será
considerado.
4. A data final de entrega é 23/6/2016.
BIBLIOGRAFIA SUGERIDA:
FIORIN, José Luiz. Introdução à linguística. 5. ed. São Paulo:
Contexto, 2008.
FRANCHI, Carlos. Mas o que é mesmo gramática? São Paulo:
Cortez, 2006.
MARTELOTTA, Mário Eduardo (Org.). Manual de linguística. 1. ed.
São Paulo: Contexto, 2010.
VIEIRA, Silvia Rodrigues Vieira; BRANDÃO, Sílvia Figueiredo.
Ensino de gramática: descrição e uso. São Paulo: Contexto, 2007.

Acreditamos que levar a sério o ensino/aprendizagem da língua materna pressupõe um professor que tenha conhecimento linguístico, embasamento teórico para tal, mas, como destaca a epígrafe a esta seção, que também saiba "tocar", ou seja, "redigir de maneira satisfatória, interpretar, esclarecer a língua de um texto, que saiba e goste de narrar, descrever e argumentar" (ILARI e BASSO, 2007, p. 235). Queremos formar professores que tenham a essência de um pesquisador: o nunca estar satisfeito com as respostas que obteve, procurando sempre outras respostas plausíveis a sua hipótese, as quais gerarão também outras tantas perguntas. Assim, serão capazes de trabalhar a língua materna com seus alunos como um fenômeno a explorar.

\section{Outro}

Em DII, os objetivos pressupõem refletir sobre o ensino da gramática, analisar, selecionar e organizar materiais didáticos apropriados à análise e reflexão sobre a linguagem em uso bem como construir procedimentos de ensino de tópicos relevantes para o ensino da língua portuguesa. Oferecida aos acadêmicos do quinto semestre da licenciatura em letras, a disciplina é semipresencial (SP), o que, por si só, já conduz à busca da autonomia, porque os alunos precisarão aprender a gerenciar seus 
momentos de estudo fora da sala de aula, sem a presença constante da professora, mesmo que ela determine horários para orientações síncronas ou assíncronas.

A redação do ensaio, no entanto, é presencial porque é exigência das disciplinas SP que a principal avaliação assim o seja. A proposta de redação orienta para uma reflexão, a partir das leituras feitas na disciplina, sobre o saber necessário para um professor de $\mathrm{PB}$, e o trabalho é dividido em três etapas, que compreendem três aulas presenciais: orientação para o ensaio e redação do resumo; redação da versão rascunho; e redação da versão definitiva. A primeira etapa acontece em sala de aula, e o resumo é, posteriormente, enviado pelo AVA. A segunda e a terceira acontecem no laboratório de informática, sendo a versão rascunho enviada pelo AVA para revisão. A definitiva, redigida no laboratório de informática, a partir das observações da professora, é, então, impressa e entregue. Na revisão, procuramos orientar tanto para a adequada utilização da variante padrão do PB quanto para a necessária autoria no conteúdo do ensaio. O Quadro 9 apresenta as orientações para a tarefa.

Quadro 9. Orientações para o ensaio sobre o saber necessário para o professor de PB

\section{PESQUISA E REDAÇÃO DE ENSAIO DOCUMENTADO}

\section{INSTRUÇÕES:}

1. Valha-se dos textos sobre ensino de leitura, gramática e produção textual trabalhados nesta disciplina* para pesquisar sobre o conhecimento necessário ao(à) professor(a) de LP para "desenvolver a competência comunicativa dos usuários da língua (falante, escritor / ouvinte, leitor)".

2. Utilize os dados de sua pesquisa para redigir um ensaio documentado, cuja estrutura pode ser encontrada em MORENO Cláudio; GUEDES, Paulo Coimbra. Curso básico de redação. São Paulo: Ática, 1986

3. O resumo a ser enviado pelo Moodle deverá ter a seguinte estrutura:

a) Organização em um parágrafo.

b) Apresentação do tema e dos objetivos da discussão.

c) Especificação da bibliografia utilizada.

d) Indicação das palavras-chave (de três a cinco).

\section{EXEMPLO:}

RESUMO: Nosso artigo contempla questões relacionadas com o domínio da língua materna, o papel da escola e do professor de português e os avanços da ciência linguística refletidos na inadequação metodológica no ensino da leitura e da produção de textos. Buscamos, por um lado, focalizar os equívocos metodológicos que minimizam a importância de um trabalho multissígnico que estimule o desenvolvimento das quatro habilidades linguísticas básicas: ouvir, falar, ler e escrever, e, por outro, incentivar o trabalho docente de pesquisa interativa em sala de aula. Em nossas pesquisas, vimos testando a eficiência dos subsídios teóricos da Semiótica de Pierce como enriquecedora do estudo das linguagens em geral e da análise linguísticas, em especial. Por fim, tentamos demonstrar, por meio de uma análise de texto, esquema de trabalho que vem sendo desenvolvido com êxito em turmas do 10 ao $4^{\circ}$ graus de ensino.

PALAVRAS-CHAVE: gramática; metodologia; semiótica aplicada Adaptado de: SIMÕES, D. M. P. (1999). Metodologia do ensino da gramática sob bases semióticas. Linguagem \& Ensino, 2(1), p.107-122.

4. Não copie trabalhos já prontos, pois seu ensaio não será considerado.

\footnotetext{
* Por que (não) ensinar gramática na escola" (POSSENTI, 1996); "Questões envolvidas na análise de textos" (ANTUNES, 2010): "Texto e contexto" (PAULIUKONIS, 2007); Concepção de Gramática (TRAVAGLIA, 1997).
}

A tarefa de ler e reler vários textos, conferindo sua autenticidade e correção, é trabalhosa, mas necessária. $\mathrm{Se}$ estivermos lidando com licenciandos em letras e quisermos que, ao chegarem à escola, sejam capazes de transformar suas salas de aula em laboratórios de aprendizagem, precisaremos também servir-lhes de modelo. Assim, demonstrar que um texto não está pronto na primeira versão indica que deverá ser lido, refeito, relido, refeito tantas vezes quantas forem necessárias até que cheguemos à versão adequada, e isso demanda trabalho. Significa dizer que talvez tenhamos de nos desacomodar e lutar, mesmo que, às vezes, a luta pareça vã, e a realidade da desvalorização da tarefa do professor nos bata à porta. No Quadro 10, trazemos trechos de um dos ensaios de DII, nos quais percebemos a angústia que acompanha todos nós, os professores de língua materna, em uma realidade que não nos é favorável.

Quadro 10. Trecho de ensaio sobre o saber necessário para o professor de PB baseado em "Por que (não) ensinar gramática na escola" (POSSENTI, 1996) e "Concepção de Gramática" (TRAVAGLIA, 1997)

Possenti diz que língua não se ensina, se aprende, mas inicia o seu texto afirmando "o papel da escola é ensinar língua padrão". À medida que se avança na leitura do texto, sua proposta fica clara e de muito bom senso, como ele mesmo a define. Porém, para quem pretende ser professor, suas ideias soam como utópicas, e aplicá-las em sala de aula exigiria uma mudança profunda no sistema de ensino, desde o maternal até as universidades, passando pelas bancas de vestibulares e de concursos públicos, e isto, naturalmente, não depende apenas do professor.

[...]

Ambos trazem como propostas o desenvolvimento das competências linguísticas dos alunos, o que para nós, estudantes, é o que realmente importa: aprender como atingir essa meta. Para que possamos cogitar essa possibilidade, muitos saberes nos serão necessários, independente do campo teórico que eventualmente venhamos a escolher (será que poderemos escolher?) para desenvolver nosso trabalho.

(Catarina Machado*)

*A aluna autorizou a publicação

Temos aqui alguém que lê, interpreta, reflete e se posiciona. A autoria está fortemente marcada pela utilização de operadores argumentativos, como "mas" (linha 1), "à medida que" (linha 3), "como" (linha 4), "porém" (linha 4); de modalizadores, como "naturalmente" (linha 9), "realmente" (linha 14), "eventualmente" (linha 17); de uma pergunta que, talvez, soe como retórica - "será que podemos escolher?" (linha 18). É este o profissional que queremos formar, que vai se desacomodar na sua prática e nos desacomodar nas salas de graduação, permitindo o debate e o contraponto, a discussão, enfim, tão saudável em qualquer área do conhecimento. 


\section{Considerações finais}

As aulas de/sobre língua materna devem envolver os diversos gêneros por meio dos quais se manifesta a linguagem, levando à discussão sobre a importância da adequação linguística às mais variadas situações comunicativas. No caso do EM, enquanto pesquisam, leem e escrevem, os alunos discutem a melhor forma de expressar suas ideias, o que demanda, então, a busca por uma linguagem mais acurada e sedutora. Estarão, dessa forma, sem que percebam, internalizando as regras do bom funcionamento da língua. A gramática passará da penosa decoreba para a prazerosa descoberta das formas eficientes de/para "dizer" o mundo.

Nem tudo foram flores, no entanto, nas experiências aqui relatadas. No projeto "Dicionário da Linguagem do MSN", por exemplo, muitos alunos não entenderam o trabalho $\mathrm{e}$ tacharam-no de "matação de aula", especialmente os das terceiras séries, que acreditavam não estar sendo preparados para o vestibular. Isso provocou a professora a repensar a estratégia para aquela série, mas não invalidou a experiência, porque, apesar das reclamações, houve aproveitamento por uma boa parte das turmas. O Quadro 11 traz uma das várias mensagens recebidas após estes mesmos alunos terem prestado as provas do vestibular.

Quadro 11. Mensagem recebida via e-mail pela professora

Data: $16 / 12 / 08$ 11:57

Assunto: PUC

Oi profe! Olha como são as coisas, a formatura nem passou e eu já estou com saudades do colégio e principalmente de ti!

Queria te informar sobre o meu desempenho em Língua

Portuguesa e Redação no vestibular da PUCRS, porque acredito,

sinceramente, que eu não faria nem a metade da pontuação sem

a tua ajuda! Então é isso: gabaritei a prova de Português e atingi

Grau 5 na Redação (o mais alto)!

Agradeço-te infinitamente profe, e fique sabendo que essa

conquista não é somente minha, é nossa!!!

Um grande beijo e espero te ver amanhã e quinta-feira também!

Também nos ensaios produzidos nas aulas da graduação houve situações de desconforto, especialmente com aqueles alunos que ainda se valem do "recorta e cola", mas os trabalhos autorais superam a expectativa e indicam que estamos no caminho certo. O resultado, apesar dos problemas, é sempre positivo, e a desacomodação, como dissemos antes, é necessária e saudável, porque exige de nós mais reflexão, mais estudo, mais pesquisa.

É essa cultura que queremos compartilhar com esses futuros professores para que eles possam perceber que o público-alvo do ensino básico não processa os conhecimentos adquiridos na escola porque não os percebe ligados ao mundo em que vive e, muito menos, ligados entre si.
Nosso papel, então, é mostrar a estudantes do ensino básico e a licenciandos em letras a funcionalidade daquilo que aprendem/aprenderam na escola/na graduação. Assim, quem sabe, possamos vencer a "guerra" contra os que acreditam que saber identificar os tipos de substantivo, por exemplo, capacitará nossos alunos a produzir bons textos. Para encerrar o relato dessas experiências, reportamo-nos, mais uma vez, ao depoimento de quem é, afinal, a razão de nosso trabalho. No Quadro 12, a análise do semestre letivo feita por um dos alunos de DII.

Quadro 12. Avaliação do semestre letivo por um aluno da graduação

A disciplina foi muito útil para esclarecer várias dúvidas acerca da metodologia em sala de aula. Os textos serviram como um suporte muito positivo nesse aspecto, e a produção do Ensaio apenas solidificou ainda mais o que foi estudado ao decorrer do semestre.

\section{Referências}

ANTUNES, I. Análise de textos: fundamentos e práticas. São Paulo: Parábola, 2010.

BONINI, A. A relação entre prática social e gênero textual: questão de pesquisa e ensino. Veredas, UFJF, v. 11, n. 2, p. 1-21, 2007.

CUNHA, A. F. Funcionalismo. In: MARTELOTTA, M. E. (Org.). Manual de linguística. São Paulo: Contexto, 2010.

FIORIN, J. L. Introdução à linguística. 5. ed. São Paulo: Contexto, 2008.

FRANCHI, C. Mas o que é mesmo gramática? São Paulo: Cortez, 2006.

KOCH, I.; ELIAS, V. M. Ler e escrever: estratégias de produção textual. São Paulo: Contexto, 2010.

ILARI, R.; BASSO, R. O português da gente: a língua que estudamos a língua que falamos. São Paulo: Contexto, 2007.

LAGO JR., S. O ofício do ensaísta. Logos - Comunicação e Universidade, Rio de Janeiro, v. 7, n. 13, p. 5-9, 2o sem. 1990.

MARCUSCHI, L. A. Produção textual, análise de gêneros e compreensão. São Paulo: Parábola, 2008.

MARTElOTTA, M. E. (Org.). Manual de linguística. São Paulo: Contexto, 2010.

MENEGHETTI, F. K. O que é um ensaio-teórico? RAC Revista de Administração Contemporânea, p. 320-332, mar.abr. 2011.

MORENO, C.; GUEDES, P. C. Curso básico de redação. São Paulo: Ática, 2004.

MOTTA-ROTH, D. O ensino de produção textual com base em atividades sociais e gêneros textuais. Linguagem em (Dis)curso, v. 6, n. 3, p. 495-518, 2010.

PAULIUKONIS, M. A. Texto e contexto. In: VIEIRA, S. R. V.; BRANDÃO, S. F. Ensino de gramática: descrição e uso. São Paulo: Contexto, 2007.

POSSENTI, S. Por que (não) ensinar gramática na escola. Campinas: Mercado de Letras, 1996. 
ROUSSEAU, J. J. Ensaio sobre a origem das línguas. Tradução Fulvia M. L. Moretto. 2. ed. Campinas: Editora UNICAMP, 2003.

SILVA. A. M. M. Manual de Funcionamento e Estrutura da Lingua Portuguesa II (apostila). Porto Alegre: Faculdade de Letras, PUCRS, 2016.

SIMÕES, D. M. P. Metodologia do ensino da gramática sob bases semióticas. Linguagem \& Ensino, v. 2, n. 1, p. 107-122, 1999.

TRAVAGLIA, L. C. Gramática e Interação. 3.ed. São Paulo: Cortez, 1997.
VIEIRA, S. R. V.; BRANDÃO, S. F. Ensino de gramática: descrição e uso. São Paulo: Contexto, 2007.

UNIVERSIDADE DO VALE DO ITAJAÍ. Produção acadêmico-científica [recurso eletrônico]: a pesquisa e o ensaio. Itajaí: [Universidade do Vale do Itajaí]. 133 fl. il. (Cadernos de ensino - Formação continuada. Ensino Superior - ano 7, n. 9, 2011).

Recebido: 31/10/2017 Aprovado: 29/11/2017 Contato: ana.silva@pucrs.br (Ana Márcia Martins da Silva) 